Journal of Applied Sciences, Engineering and

Technology for Development. Volume 2, Issue 1

Research Article

ISSN 2309-0936

\title{
MODELLING OF POTENTIAL SITES FOR UNDERGROUND WATER IN SEMI ARID AREAS
}

\author{
MUNDIA*, C.N \& NJAGI N. W \\ Dedan Kimathi University of Technology. P. O. Box 657-10100, Nyeri, Kenya.
}

Received January 2018 Revised March 2018 Accepted April 2018

\begin{abstract}
Kajiado County in southern Kenya experiences insufficient amount of rainfall and people living in this region face alot of water challenges. The main economic activities in the area include pastoralism, livestock herding, tourism and agriculture which require sustainable water sources. The current water sources in the area are mainly seasonal rivers that provide unreliable water supply. The few existing boreholes are long distances apart. Amount of rainfall experienced in this region is insufficient and unreliable. This study sought to identify alternative, reliable, and sustainable water sources to complement the current unreliable water sources. Underground water is sustainable and its identification and utilization could help in solving the current water issues.

To address the problem of water shortage, Remote Sensing and GIS techniques were applied in analyzing and identifying suitable sites for underground water. Necessary variables for identifying underground water were identified with assistance from expert opinion. Current water resources were characterized, a geodatabase created and a model for underground water developed. Land cover, slope, lithology, soil, lineament and climate comprised the six variables used. GIS technology was integrated with Analytical Hierarchy Process (AHP), for Multi Criteria Evaluation (MCE) in determining the factors necessary in locating suitable areas. Identified criteria were combined using weighted overlay approach.

Results indicated that $51 \%$ of the study area was viable for sourcing underground water. Exploitation of this resource would mean sustainable source of water. The suitable locations were well distributed in the County except in the central area which generally falls under unsuitable areas for sourcing underground water. Remote Sensing and GIS were noted as suitable tools for identifying suitable locations for sourcing underground water. Decision makers could adopt this approach in making informed decisions on where to sink new boreholes.
\end{abstract}

Keywords: AHP, GIS modeling, Kajiado County, suitable site selection, underground water

\footnotetext{
*Correspondence to: Charles Mundia, Dedan Kimathi University of Technology, P.O. Box 657-10100, Nyeri-Kenya. Email: ndegwa.mundia@gmail.com

MUNDIA \& NJAGI: Modeling of potential sites for underground water in semi-arid areas
} 


\section{Journal of Applied Sciences, Engineering and Technology for Development. Volume 2, Issue 1}

\section{INTRODUCTION}

Water is a vital resource for agriculture, domestic water supply and industry. It is also crucial for irrigation and plays a critical role in maintaining agricultural production during droughts. The Country's natural water resources do not provide equitable delivery of water and the water basins do not supply adequate water, leaving most of the population without fresh water supply (Snyder, 2016). Inadequate and inequitable access to water is both a result and cause of poverty and can be termed as denial of human rights, good health, adequate nutrition, literacy and employment (Teresia et. al., 2014). Access to clean water is essential for maintaining good health and for agricultural activities for sustainable food production. Teresia et al., (2014) further stated that access to safe drinking water is also very critical to the attainment of the Millennium Development Goals specifically, the eradication of extreme poverty and hunger, improving maternal health, achieving universal primary education, promoting gender equality, empowerment of women, and reducing child mortality.

Rural areas in Kenya are worst effected and without sufficient water. This water shortage means that a majority of people, especially women and children spend most of their time searching for water. Nearly half of the country's inhabitants are vulnerable (Snyder, 2016). Marshall (2011) noted that of the 40 million people living in Kenya, 43 percent had no access to clean water. For decades, Kenya has suffered from severe water crisis due to various causes; among them the frequent droughts, degradation of forests, lack of water supply management, water contamination, and the increasing human population. Inadequate rainfall or lack of it affects ability to acquire food. This has resulted to eruptions of violence among some Kenyan communities. In many areas, the shortage of water has been amplified due to failure to investment in water supply, especially in rural areas. With growing population there would be need to tackle this water crisis and its effects (Marshall, 2011).

Ground water resource is an important natural resource for domestic use, agriculture, and for industrial applications. There has been a tremendous increase in the demand for ground water due to various factors including the increasing human population, advanced irrigation practices and industrial usages. Groundwater is presently a significant natural resource, but of limited use due to various factors including frequent failures in rainfall, undependable surface water, and rapid urbanization and industrialization, which have created major risks to this valuable resource (Ramamoorthy et al., 2015). Groundwater and surface water are closely connected in both arid and humid environments (Brutsaert, 2005). According to Kuria et al., (2012), groundwater and its development can play a big role in a country's economy. It becomes a usable resource when the water bearing formations are permeable enough to allow water to infiltrate through them, to yield adequate quantity of good quality water for use through boreholes, hand dug-wells, and springs. This underground water could be replenished from recharge sources to permit continued exploitation.

Water shortage in arid regions has been aggravated by global climate change that is predicted to severely impact marginal regions. Exploration, mapping, and monitoring of underground water resources are a prerequisite for the availability, accessibility, fair utilization, and rational management of water resources in arid and semi-arid regions (Asadi et al., 2012, Sharma, 1998 and Yan et al., 2010). Groundwater could therefore be exploited if potential areas with abundant quantity could be identified.

\section{MUNDIA \& NJAGI: Modeling of potential sites for underground water in semi-arid areas}




\section{Journal of Applied Sciences, Engineering and Technology for Development. Volume 2, Issue 1}

The objective of this study therefore was to model for potential sites for underground water in marginal areas as a solution to the current water challenges in Kenya.

\section{METHODS}

\section{Study Area}

The study area (Figure 1) covers an area of about 21,901 square kilometers and is divided into five administrative sub-counties. The County falls within the Kenyan Rift Valley. The County is generally arid or semi-arid and experiences temperature ranges of between $20^{\circ} \mathrm{C}-30^{\circ} \mathrm{C}$ and average annum of rainfall of $500 \mathrm{~mm}$ to $1,250 \mathrm{~mm}$. The region enjoys two wet seasons, the 'short rains' between October and December and the 'long rains' between March and May. The County is home to Amboseli National Park, a popular tourist destination rich in wildlife and with diverse ecosystems. The county population according to the latest population census in 2009 stood at 687,312 persons.

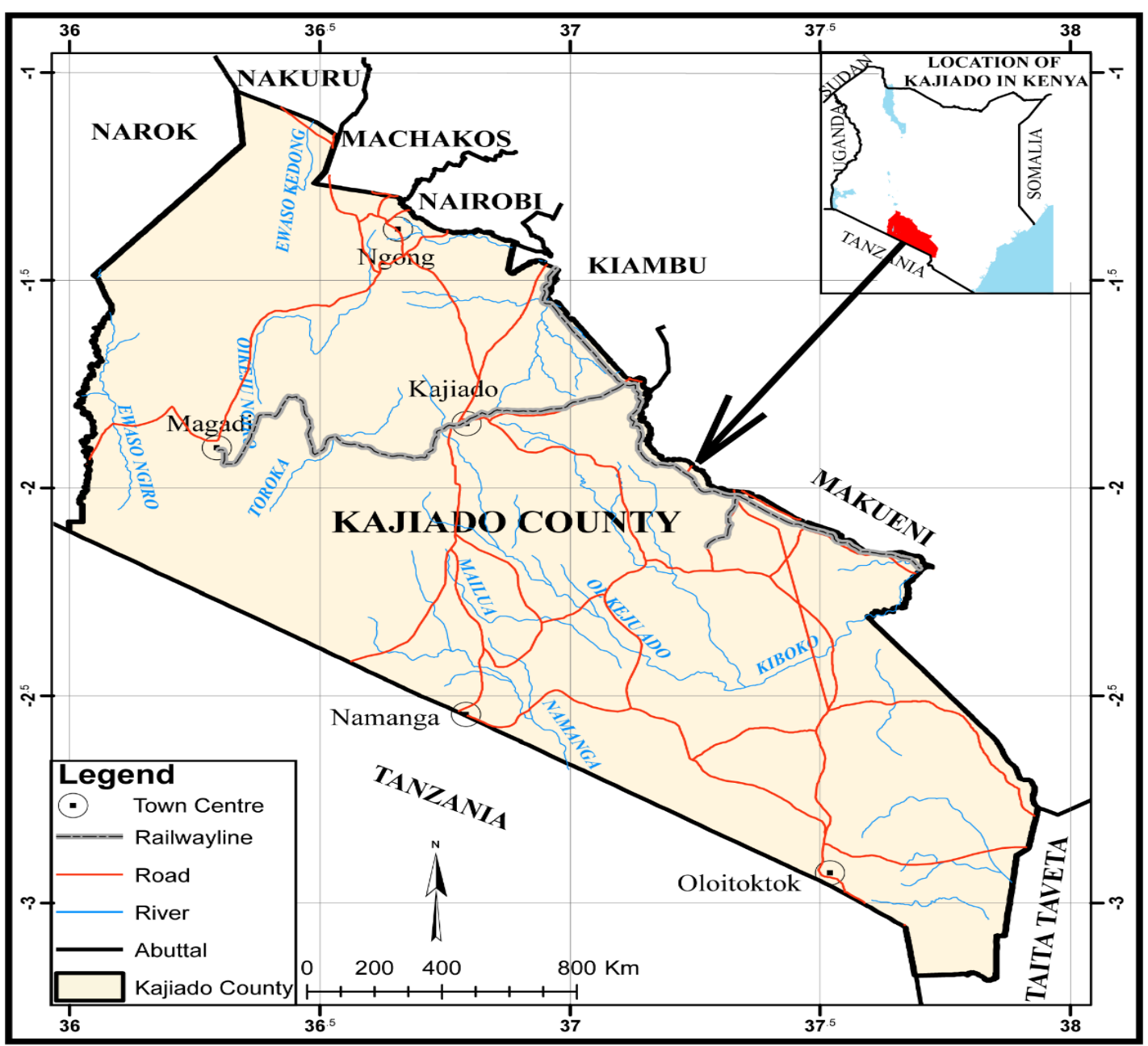

Figure 1: Map of the study area

\section{Data Sets and Materials}

The required datasets were obtained from different sources. Climate data used for generating rainfall and temperature variables was sourced from the Kenya 


\section{Journal of Applied Sciences, Engineering and Technology for Development. Volume 2, Issue 1}

Meteorological Department. The data collected covered duration of 30 years. Soil data was sourced from Kenya Soil Surveys. The soil data was used to obtain soil drainage, soil depth and texture. Landsat 8 satellite images, Shuttle Radar Topographic Mission (SRTM) images covering the study area were downloaded from USGS website. Lithology data was acquired from International livestock Research Institute (ILRI). The base map data was sourced from Survey of Kenya, while the existing borehole data was sourced from WARMA. Table 1 summarizes the datasets used for this study.

Table 1: Datasets used for this study

\begin{tabular}{|c|c|c|c|}
\hline Data & Source & Type & Resolution \\
\hline Lineament & $\begin{array}{l}\text { Mines and Geology } \\
\text { Department }\end{array}$ & Tiff Image & Map of Kenya \\
\hline $\begin{array}{l}\text { Administrative } \\
\text { boundaries }\end{array}$ & Survey of Kenya & Shapefile & Scale 1:50000 \\
\hline Lithology & $\begin{array}{l}\text { International Livestock } \\
\text { Research Institute (ILRI) }\end{array}$ & Shapefile & Map of Kenya \\
\hline Hydrology & Ministry of water & Excel & Current \\
\hline Satellite imagery & USGS & Image & $30 \mathrm{~m}$ \\
\hline Climate data & $\begin{array}{l}\text { Kenya Meteorological } \\
\text { Department }\end{array}$ & Excel & 30 years \\
\hline Soil Data & Kenya Soil Surveys & Shapefile & Recent \\
\hline Questionnaire & Interviewing Experts & Table & Current \\
\hline
\end{tabular}

\section{Research approach}

The study methodology is presented in Figure 2 and represents the approach adopted in locating suitable sites for underground water. The procedure involved determining the factors involved in locating best sites. Identified data was collected after which it was prepared and processed. Data preparation and processing entailed data standardization, geo-database creation data modelling and analysis. Data harmonization and standardization involved transformation of spatial data to a uniform datum and projection while geo database creation entailed data vectorization, geo-referencing, digitization and rasterization and reclassification of factors. The spatial analyst tools in ArcGIS were applied to perform spatial analyses. This was followed by creation of Analytical Hierarchical Process and the integration of Multi Criteria Evaluation within GIS to generate an underground suitability map.

A model was used in organizing elements of data and standardized how they relate with one another and to properties of the real world entities. It enabled the representation of real geographical elements as graphical elements. The model was used in conjunction with GIS to analyze and lay out data. Model builder in ArcGIS Spatial Analyst was used to identify suitable locations for underground water. Manipulation of information in the model occurred in multiple steps representing stages in complex analysis procedure. The first step involved deriving slope, Euclidean distance to lineaments, convert polygons to raster, clipping of data to area of study, interpolating rainfall and temperature data. The second step involved reclassifying the derived datasets to a common scale. The third step weighed the

\section{MUNDIA \& NJAGI: Modeling of potential sites for underground water in semi-arid areas}




\section{Journal of Applied Sciences, Engineering and Technology}

for Development. Volume 2, Issue 1

datasets depending on the percentage of influence. After weighing, the datasets were combined through modeling to produce suitable locations of underground water.

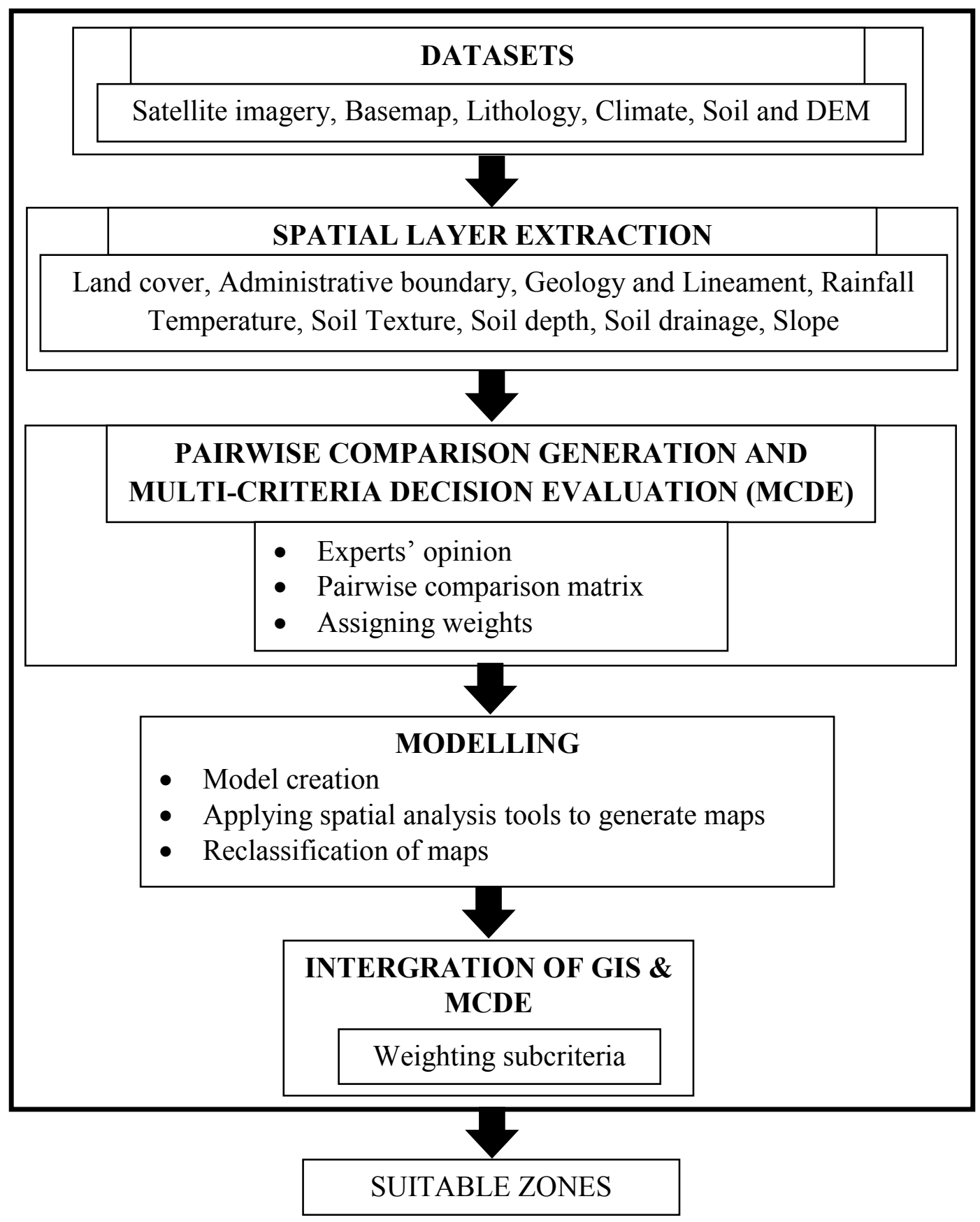

Figure 2: The study approach

\section{RESULTS AND DISCUSSION}

Suitability variables

The results for land cover mapping are represented in Figure 3. The areas with thick vegetation cover protect underground water loss by preventing evaporation in comparison to bare land which allows evaporation. Presence of underground water MUNDIA \& NJAGI: Modeling of potential sites for underground water in semi-arid areas 


\section{Journal of Applied Sciences, Engineering and Technology for Development. Volume 2, Issue 1}

would be more favorable in forested areas as compared to bare land. The four (4) major classes of rock types that resulted from lithology classification were unconsolidated rocks, sedimentary rocks, metamorphic rocks and igneous rocks as shown in Figure 4.

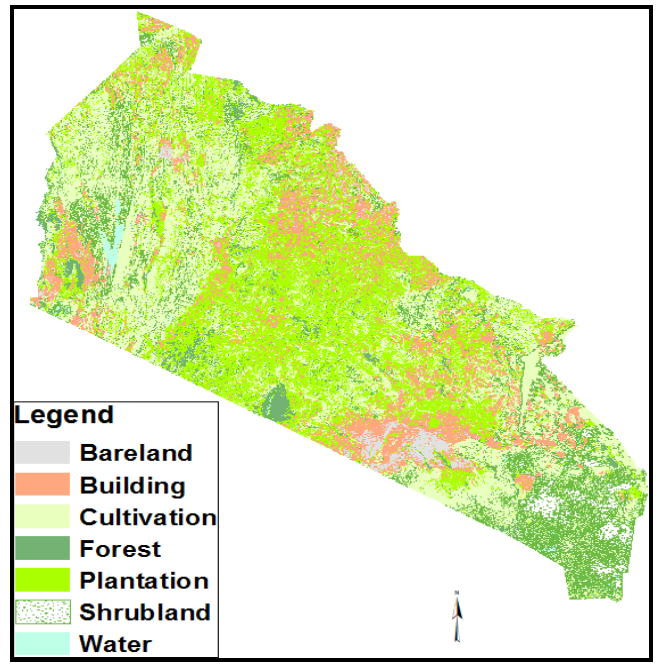

Figure 3: Land cover map

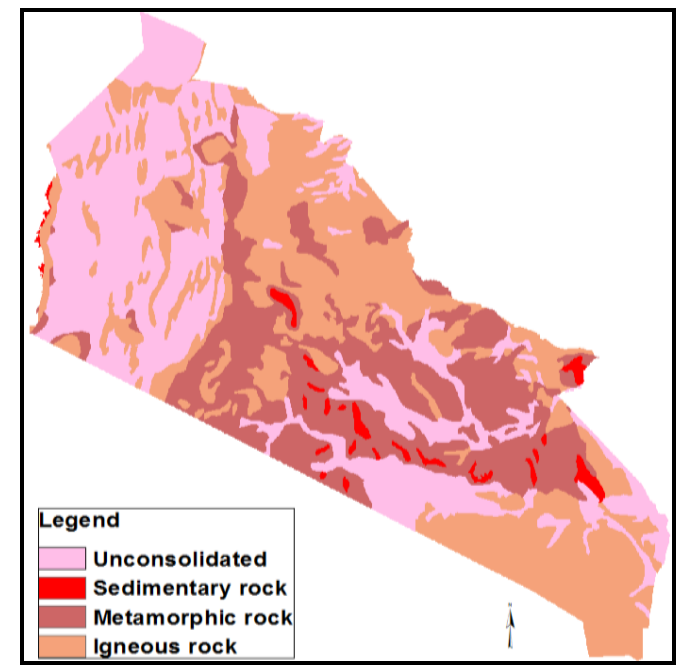

Figure 4: Map of classified Lithology

Climate data collected and interpolated showed that temperature in the study area ranged from $16^{\circ} \mathrm{C}$ and $25^{\circ} \mathrm{C}$ as shown in Figure 5. Figure 6 presents rainfall which ranged between $(464 \mathrm{~mm}-1045 \mathrm{~mm})$. This represented the mean for the 30 year period.

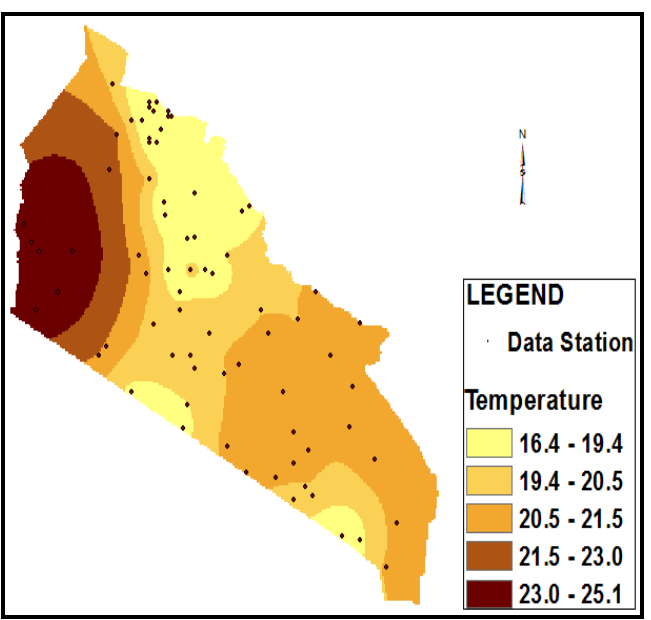

Figure 5: Temperature map

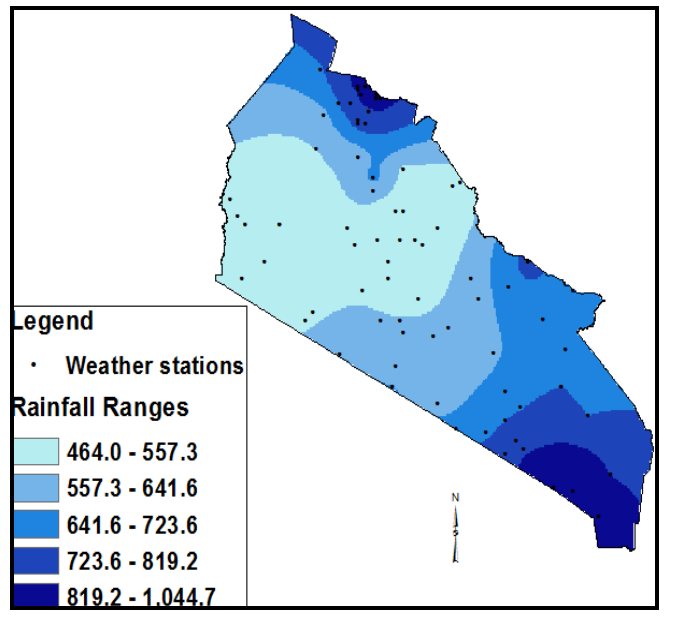

Figure 6: Rainfall map

The classified slope map is presented in Figure 7. The slope was developed from the downloaded SRTM Digital Elevation Model. The slope in degrees ranged from 0 - 74. Three classes of soil were weighted to derive a weighted soil map shown in Figure 8. The two classes of soil generated was class 1 representing the unsuitable areas and class 2 representing the suitable areas 


\section{Journal of Applied Sciences, Engineering and Technology}

for Development. Volume 2, Issue 1

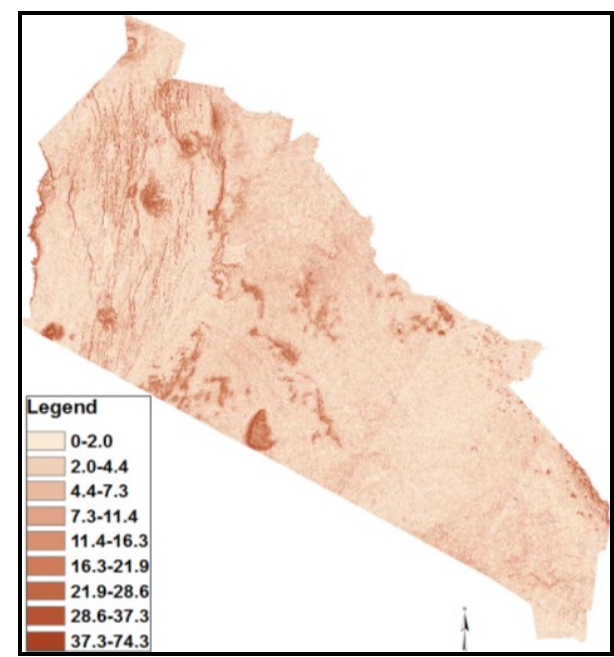

Figure 7: Classified slope map

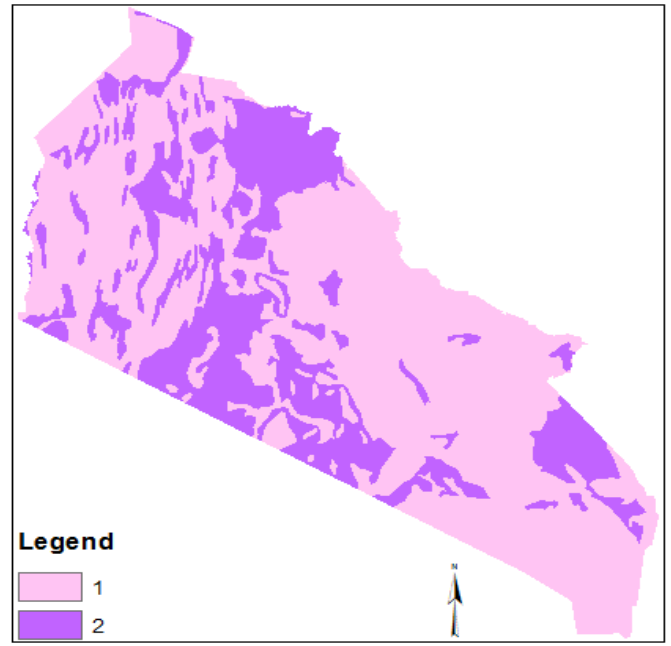

Figure 8: Soil map

\section{Spatial modelling}

Spatial model that involved interpolation was applied in ArcGIS. Operations as noted included, polygon to raster conversion, clipping, reclassification and weighted overlay. Connectors were added between the model's output and the operation tool and the model thereafter run. Large voluminous files were processed automatically. The model was run involving different steps to create the suitability map of underground water shown in Figure 9.

Six parameters used in this study were all weighted depending on their importance. The percentages assigned depending on the importance are shown in Table 2.

Table 2: Weights applied for overlay analysis.

\begin{tabular}{ll} 
Criteria & Importance (\%) \\
\hline Land cover & 37 \\
Slope & 27 \\
Soil & 12 \\
Lithology & 13 \\
Climate & 4 \\
\hline
\end{tabular}

Highly suitable areas and the moderately suitable areas are potential areas suitable to attain underground water. Figure 9 and Table 3 indicate that Kajiado North is generally highly Suitable or moderately suitable (74\%) and has the highest suitability for underground water. This could be explained by the region bordering natural forests to the north, which are near the Aberdare ranges and therefore attracts rainfall allowing underground recharge. These results indicate that Kajiado County has underground water that could be exploited to allow sustainable development. The suitability levels in the sub counties within the study area are presented in Table 3. 
Journal of Applied Sciences, Engineering and Technology for Development. Volume 2, Issue 1

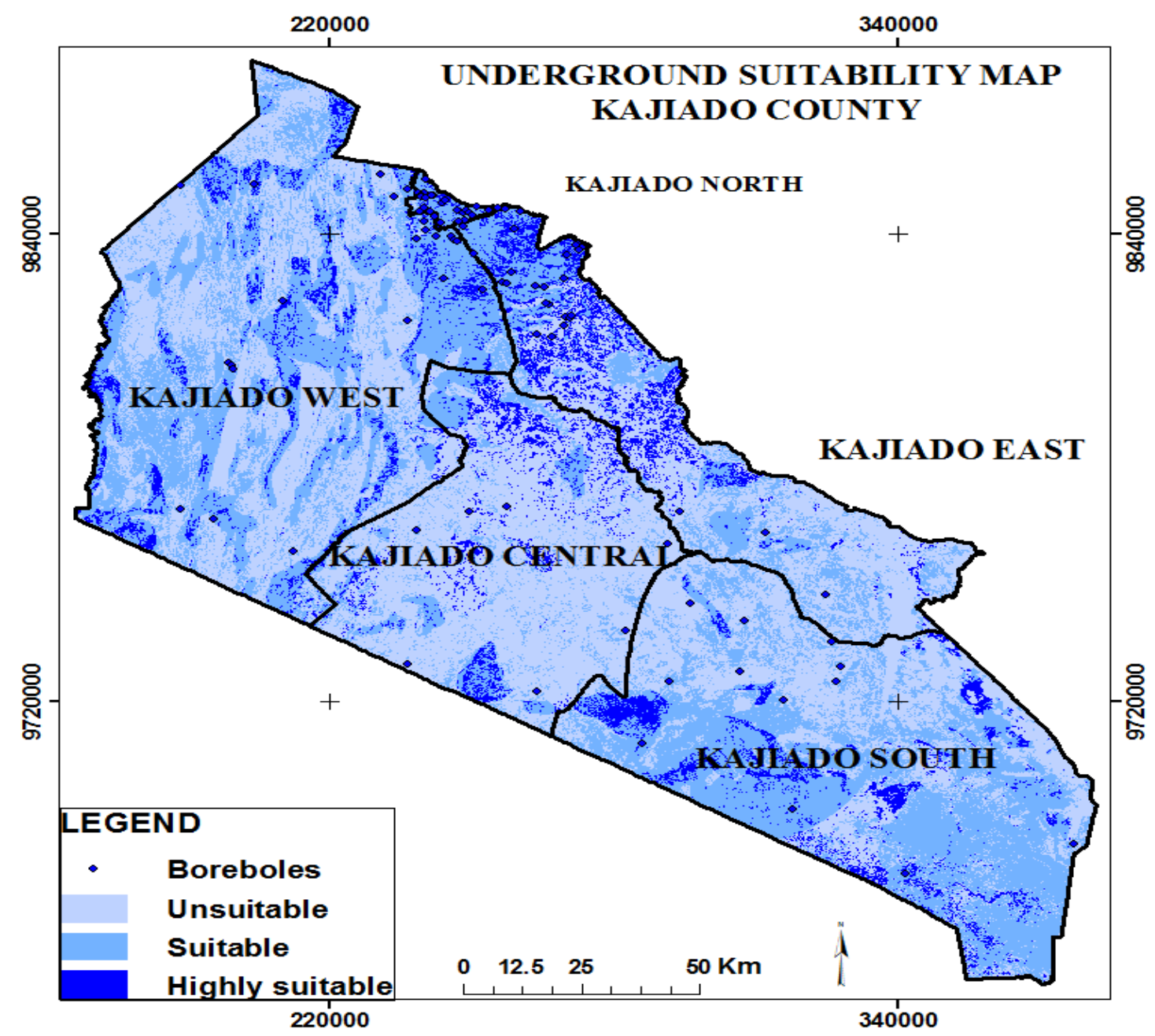

Figure 9: Generated underground water suitability map

Table 3: Suitability levels per sub counties in the study area

\begin{tabular}{llll}
\hline Suitability Class & Constituency & Area (ha) & Area (\%) \\
\hline Highly Suitable & Kajiado North & 2813.25 & 26 \\
& Kajiado East & 56815.26 & 18 \\
& KajiadoWest & 60362.81 & 8 \\
& KajiadoCentral & 34366.9 & 8 \\
& KajiadoSouth & 51275.07 & 9 \\
\hline Moderately Suitable & Kajiado North & 7814.15 & 71 \\
& Kajiado East & 100922.5 & 33 \\
& KajiadoWest & 372790.78 & 48 \\
& KajiadoCentral & 75078.7 & 17 \\
& KajiadoSouth & 335411.97 & 57 \\
\hline Unsuitable & Kajiado North & 382.49 & 3 \\
& Kajiado East & 151075.7 & 49 \\
& KajiadoWest & 337421.8 & 44 \\
& KajiadoCentral & 319055.25 & 74 \\
& KajiadoSouth & 203020.71 & 34 \\
\hline
\end{tabular}

MUNDIA \& NJAGI: Modeling of potential sites for underground water in semi-arid areas 


\section{Journal of Applied Sciences, Engineering and Technology}

for Development. Volume 2, Issue 1

Table 4: Underground water suitability levels

\begin{tabular}{|l|l|r|r|}
\hline Kajiado County & Suitability Level & \multicolumn{1}{|c|}{ Area (ha) } & Area (\%) \\
\cline { 2 - 4 } & Highly Suitable & 205640.372 & 10 \\
\cline { 2 - 4 } & Moderately Suitable & 892025.298 & 42 \\
\cline { 2 - 4 } & Unsuitable & 1010960 & 48 \\
\hline
\end{tabular}

\section{CONCLUSION}

Arid and semi arid areas in Kenya experience a high level of water scacity. This is attributed to insufficient rainfall. The water scacity has led to competion for this scarse resource by humans as well as wildlife and domestic animals. This competition has brought about violent conflicts as communities compete for water. It has become crucial to identify the locations of underground water to try and met this need. This study sought to model potential sites for underground water in the semiarid Kajiado County to provide solution to the serious water challenges. Six variables that influence underground water resource were identified. These variables included land cover, slope, lithology, soil, lineament and climate. The variables were sourced, processed, standardized and overlaid. Rainfall and temperature data covered a span of 30 years. Mean rainfall and temperatures were calculated, spatial data located, interpolation carried out and model run and weighted to derive climate map. Slope dataset was extracted from DEM acquired from Shuttle Radar Topographic Mission datasets downloaded from USGS website. The DEMs were mosaicked, cropped and a slope generated. Landsat 8 satellite was processed and image classifications carried out. Soil texture, drainage and depth were considered. Spatial model was created for use in the establishment of suitable sites using GIS and Remote Sensing based on Multi Criteria Evaluation. Results show that $50 \%$ of Kajiado County has potential in holding underground water. Results also show that Kajiado North is generally suitable (74\%) and has the highest suitability for underground water. This demonstrate that Remote Sensing and GIS technology when integrated with Analytical Hierarchy Process (AHP could be used to model underground water.

This study proposes that the identified suitable areas for underground water be investigated to determine extractable amounts, the depths of extraction, the quality of water and the sustainability of the underground water.

\section{REFERENCES}

Asadi, S.S., Rani, N., Vasantha, R., Raju, M.V. (2012). Estimation of groundwater potential zones using remote sensing and GIS." International Journal of Advanced Scietific Ressearch Technology, 2012: 265-275.

Brutsaert, W. (2005). Hydrology. Cambridge: Cambridge University Press.

Kuria D.N., Gachari, M.K., Macharia, M. W., \& Mungai, E. (2012). Mapping groundwater potential in Kitui District, Kenya using geospatial technologies. International Journal of Water Resources and Environmental Engineering 4, no. 1 (2012): 15-22.

\section{MUNDIA \& NJAGI: Modeling of potential sites for underground} water in semi-arid areas 


\section{Journal of Applied Sciences, Engineering and Technology for Development. Volume 2, Issue 1}

Rammohan, R (2015). Assessment of groundwater potential zone using remote sensing and GIS in Varahanadhi watershed, Tamilnadu, India. International Journal for Research and Applied Science \& Engineering Technology (IJRASET), V (2015), Issue 3: 695-702.

Marshall, S (2011). The Water Crisis in Kenya: Causes, Effects and Solutions. Global Majority E-Journal 2, no. 1 (2011): 31-45.

Sharma, K.D, Sungh, S, Singh, N, \& Kalla, A.K. (1989). Role of satellite remote sensing in monitoring of surface water resources in an arid environment." Hydrological Science, 1989: 531-537.

Snyder, S. (2016). United Nations. May 9, 2016. https://thewaterproject.org/water-incrisis-kenya.

Teresia, W.G., Agwata, J.F., \& Mulwa, R.M. (2014). Socio economic factors hindering the participation of women managing water resources in Kajiado County. Kenya. IOSR Journal of Humanities and Social Science (IOSR-JHSS) 19, no. 1 (2014): 75-85.

Yan, E., Milewski, A., Sultan, M., Abdeldayem, A., Soliman, F., Abdel, G. K. (2010). Remote sensing based approach to improve regional estimation of renewable water resources for sustainable development." Cairo, 2010. 14-17. 